\title{
Computational fluid dynamic simulation of a pulse-width modulated spray nozzle
}

\author{
Zachary Chapman, Jeffrey Doom \\ Mechanical Engineering Department, South Dakota State University, Brookings, SD, USA
}

\begin{abstract}
Computational fluid dynamics (CFD) is a useful tool used by engineers in many industries to study fluid flow. A relatively new industry to adopt the use of CFD is the agricultural industry. A spray nozzle commonly used in agricultural spraying, the Teejet 110-degree nozzle (TeeJet Technologies, 2020), was simulated. A method was developed to pulse the spray. A user-defined function was used to define the velocity at the inlet of the nozzle to pulse the spray. The domain was then extended to allow the examination of a slice 20 inches below the nozzle. The simulation results were compared to experimental results collected from a sprayer testbed. The effect of frequency was then investigated by changing the frequency of the pulses. Results from these studies show that a userdefined function can be used to pulse the spray. CFD can be used to model spray nozzles, but the validity of the results are strongly related to the computational resources available, and increasing the frequency of the pulses results in a higher concentrated spray toward the center of the spray plume. The simulations were carried out using a commercial code (CD-Adapco, 2019).
\end{abstract}

\section{Introduction}

Agricultural spraying is a complex process that is affected by many variables. One variable is the spray nozzle itself. While the spray nozzle may seem like a small part of the spraying process,

Correspondence: Jeffrey Doom, Mechanical Engineering Department, South Dakota State University, $11518^{\text {th }}$ St. Brookings, SD, USA.

Tel./Fax: +1.605.688.6703/605.688.5878.

E-mail: jeffrey.doom@sdstate.edu

Key words: Pulsed sprayer nozzles; Reynolds averaged Navier-Stokes; agricultural sprayer nozzles.

See online Appendix for additional Figures.

Received for publication: 8 July 2020.

Accepted for publication: 19 November 2020.

(C) Copyright: the Author(s), 2021

Licensee PAGEPress, Italy

Journal of Agricultural Engineering 2021; LII:1104

doi:10.4081/jae.2021.1104

This article is distributed under the terms of the Creative Commons Attribution Noncommercial License (by-nc 4.0) which permits any noncommercial use, distribution, and reproduction in any medium, provided the original author(s) and source are credited. the nozzle plays a vital role. Several costly problems such as over application, under application, and/or drift can arise from using an improper spray nozzle (TeeJet Technologies, 2013). Over application results in the waste of chemicals while under application can cause the need for respraying. The inhalation of chemicals due to drift can be harmful to humans and wildlife while also injuring or contaminating crops (United States Environmental Protection Agency, 2019). These are some of the many reasons to study spray nozzles. While research into spray nozzles has typically been done experimentally, recently there have been studies using Computational fluid dynamic (CFD) simulations which reduces the need of costly experiments and can provide additional information. Dekeyser et al. (2013) investigated the ability to accurately model air assisted sprayers using CFD as well as determine if CFD could be used to optimize the spout angle. Dekeyser found that the CFD models were successful in modeling spray patterns and optimizing the spout angle. Endalew et al. (2020) investigated the ability to move a sprayer though an orchard within a CFD simulation and found the simulation results were comparable to experimental results. Bade et al. (2010) compared CFD results of sprayers at multiple injection angles and found the CFD models corresponded well to experimental results. Sidamed et al. (2005) took a different approach by creating a virtual nozzle to study spray patterns and droplet transport.

This work looks to investigate a pulse-width modulated sprayer. Some companies claim that pulsing the spray at low frequencies provides better results while other companies claim pulsing at higher frequencies is better. This work will investigate the effect frequency has on the spray distribution characteristics by determining whether CFD can be used to study pulsed spray nozzles and simulating a spray nozzle which is pulsed at various frequencies. The paper is organized as follows. Section 2 contains the problem definition which describes the nozzle geometry and boundary conditions. Section 3 contains the results from the simulations while Section 4 provides the conclusions.

\section{Problem definition}

The present work looks to investigate the ability to simulate a pulse-width modulated spray nozzle using CFD while also investigating the effects that the frequency of the pulses has on spray distribution. A spray nozzle commonly used in agricultural spraying was studied. A CAD model of the nozzle was not readily available, so the geometry was obtained from a Computed Tomography (CT) scan that was provided by another party. The CT scan was taken using the Scanco Medical machine at University of South Dakota. The voxel size was $14.8 \mathrm{~mm}$. The spray distribution of the nozzle at a slice 20 inches $(508 \mathrm{~mm})$ below the tip of the nozzle was examined and compared to experimental data. 


\section{Model generation}

The nozzle simulated was a TeeJet 110-degree spray nozzle (TeeJet Technologies, 2020). The nozzle is a flat fan style nozzle with a 110-degree spray angle. The nozzle outlet has a shape of an oval or an eye. The diameter of the longer side of the oval is $3 \mathrm{~mm}$ and the shorter side of the oval is $0.7 \mathrm{~mm}$. The geometry of the nozzle was provided from a CT scan. A 3D slicer was used to convert the scan to an STL file then saved as a step file in Solidworks. The scan was also repaired to fill in discontinuities on the surface and body. The resulting nozzle geometry and the nozzle nomenclature can be seen in Appendix Figure 1.

The nozzle geometry was then removed from a 15.5 inch $(393.7 \mathrm{~mm})$ by 53 inch $(1346.2 \mathrm{~mm})$ rectangular geometry to simulate the air around the nozzle. The rectangular geometry was long enough to allow the visualization of the spray distribution at a plane 20 inches $(508 \mathrm{~mm})$ below the tip of the nozzle. The geometry was imported into Star-CCM+, a commonly used commercial CFD package (Siemens, 2020). Figure 1A is the geometry used during the simulation.

\section{Governing equations}

The equations that govern fluid dynamics are the NavierStokes Equations. The equations are the conservation of mass, conservation of momentum, and conservation of energy. Equations 1, 2 , and 3 are the equations for the conservation of mass, momentum and energy respectively.

$$
\frac{\partial \rho}{\partial t}+\nabla(\rho v)=0
$$

$$
\frac{\partial}{\partial t}(\rho v)+\nabla(\rho v \otimes v)=\nabla \sigma+f_{b}
$$

$$
\frac{\partial}{\partial t}(\rho E)+\nabla(\rho E \boldsymbol{v})=f_{b} \boldsymbol{v}+\nabla(\boldsymbol{v} \sigma)-\nabla \boldsymbol{q}+S_{E}
$$

\section{Reynolds averaged navier-stokes}

Simulations solving the Navier-Stokes equations directly are often referred to as direct numerical simulations (DNS). DNS are very computationally expensive (Ferziger and Peric, 2002) because all turbulent length scales are resolved. A different approach is to use the Reynolds averaged Navier-Stokes (RANS) equations where the turbulent length scales are modeled. The RANS equations are formulated by averaging variables. Equations 4, 5, and 6 are the unsteady RANS equations for conservation of mass, conservation of momentum, and conservation of energy.

$$
\begin{aligned}
& \frac{\partial \rho}{\partial t}+\nabla(\rho \overline{\boldsymbol{v}})=0 \\
& \frac{\partial}{\partial t}(\rho \overline{\boldsymbol{v}})+\nabla(\rho \overline{\boldsymbol{v}} \otimes \overline{\boldsymbol{v}})=-\nabla \overline{\boldsymbol{I}}+\nabla\left(\overline{\boldsymbol{T}}+T_{R A N S}\right)+f_{b} \\
& \frac{\partial}{\partial t}(\rho \bar{E})+\nabla(\rho \bar{E} \overline{\boldsymbol{v}})=-\nabla \overline{\boldsymbol{p}} \overline{\boldsymbol{v}}+\nabla\left(\overline{\boldsymbol{T}}+T_{R A N S}\right) \overline{\boldsymbol{v}}-\nabla \overline{\boldsymbol{q}}+f_{b} \overline{\boldsymbol{v}}
\end{aligned}
$$

The RANS equations introduce six new unknowns into the equations. This requires the use of a turbulence model which will be discussed next. For more information on the derivation of RANS equations, please refer to (CD-Adapco, 2019), (Feriger and Peric, 2002), and/or (Moukalled et al., 2016).

\section{k- $\varepsilon$ turbulence modeling}

To solve for the unknowns introduced by the RANS equations, a turbulence model must be used (Ferziger and Peric, 2002). The turbulence model used during the simulations was the k- $\varepsilon$ turbulence model. The $\mathrm{k}-\varepsilon$ turbulence model is an eddy viscosity model which models the stress tensor as a function of mean flow quantities using the concept of turbulent eddy viscosity. The model solves two transport equations for the turbulent kinetic energy and the turbulent dissipation rate in order to solve for the turbulent eddy viscosity. Equations 7 and 8 are the transport equations used to solve for the turbulent kinetic energy and the turbulent dissipation rate.

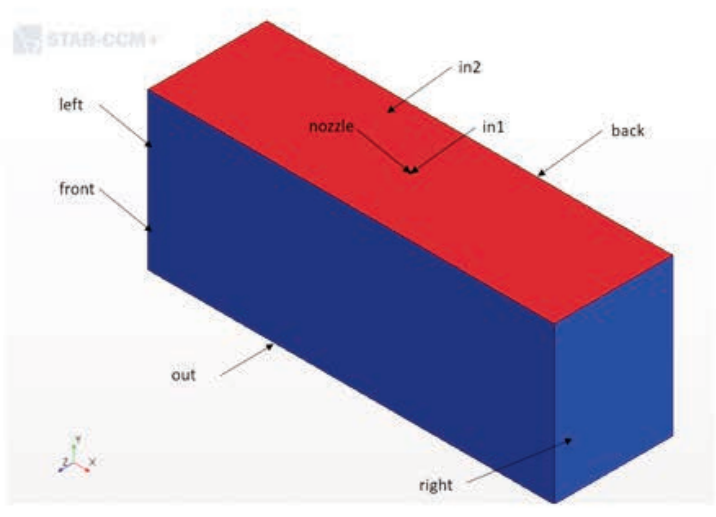

A) Geometry

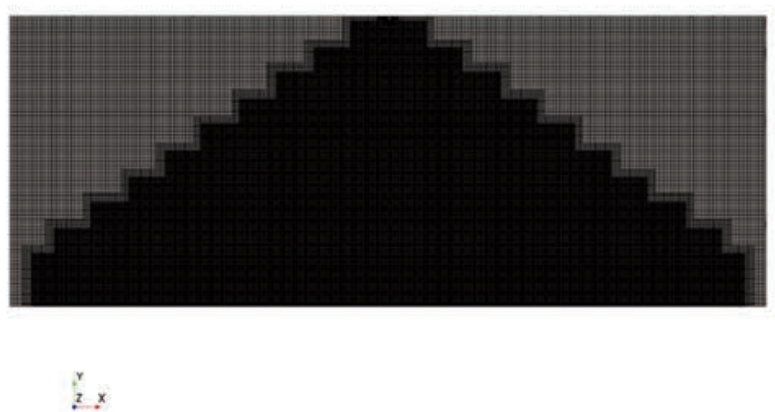

B) Mesh

Figure 1. A-B) Geometry of simulation. 
$\frac{\partial}{\partial t}(\rho k)+\nabla(\rho k \bar{v})=\nabla\left[\left(\mu+\frac{\mu_{t}}{\sigma_{k}}\right) \nabla k\right]+P_{k}-\rho\left(\epsilon-\epsilon_{0}\right)+S_{k}$

$$
\frac{\partial}{\partial t}(\rho \epsilon)+\nabla(\rho \epsilon \bar{v})=\nabla\left[\left(\mu+\frac{\mu_{t}}{\sigma_{\epsilon}}\right) \nabla \epsilon\right]+\frac{1}{T_{e}} C_{\epsilon 1} P_{\epsilon}-C_{\epsilon 2} f_{2} \rho\left(\frac{\epsilon}{T_{e}}-\frac{\epsilon_{0}}{T_{0}}\right)+S_{\epsilon}
$$

For more information on the k- $\varepsilon$ turbulence model please refer to CD-Adapco (2019), Ferziger and Peric (2002) and/or Moukalled (2016).

\section{Volume of fluid method}

The spraying process is considered to be a multiphase problem meaning multiple phases, in this case, air and water, are present. This requires multiphase modeling to be included in the simulations. There are several different multiphase modeling techniques. A popular method is the volume of fluid method (VOF). The VOF is an interface-capturing method that attempts to predict the distribution and movement of the interface between the different phases. The VOF method determines the distribution of a fluid by determining the volume fraction of the phase in the cell. Equation 9 is the equation for a phase, $i$, in a particular cell and must satisfy Equation 10.

$$
\alpha_{i}=\frac{V_{i}}{V}
$$

$$
\sum_{i=1}^{n} \alpha_{i}=1
$$

As stated previously, this application has two phases, water and air. This allows $i$ to be equal to 1 or 2 and $n$ is 2 in this case. If $i$ equal to 1 corresponds to the air phase and $i$ equal to 2 corresponds to the water phase, the phases can be found by finding the volume fraction. If the volume fraction of water is zero, the cell would be completely full of air. If the volume fraction of water is one, the cell would be completely full of water. If the volume fraction is between zero and one, the interface between the water and the air is present within the cell. For further information on the numerical methods for multiphase models, please refer to CDAdapco (2019) or Tryggvason et al. (2011).

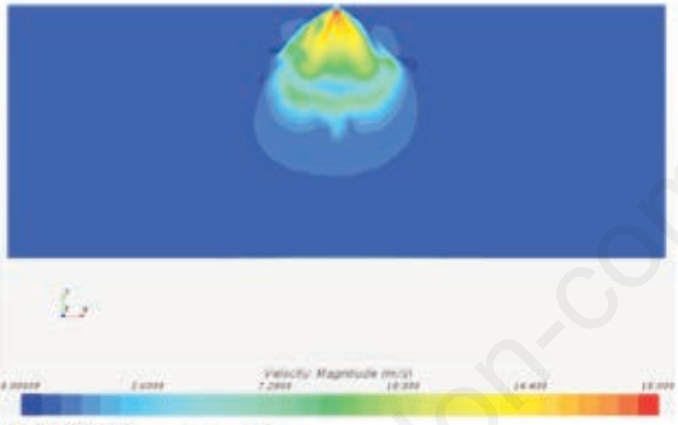

\section{A) 0.05 seconds}

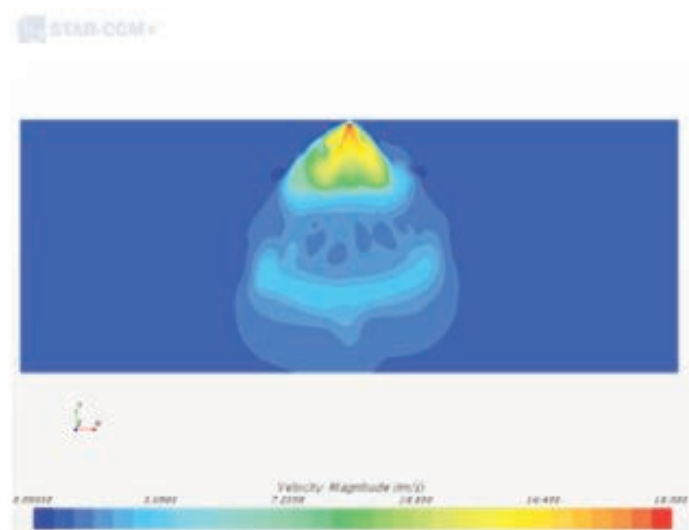

C) 0.15 seconds

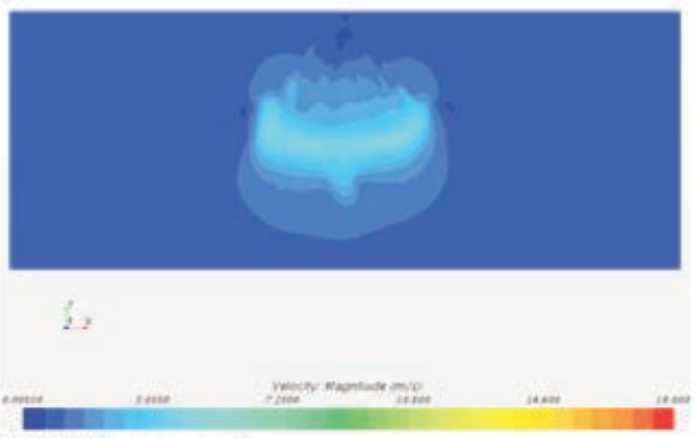

B) 0.1 seconds

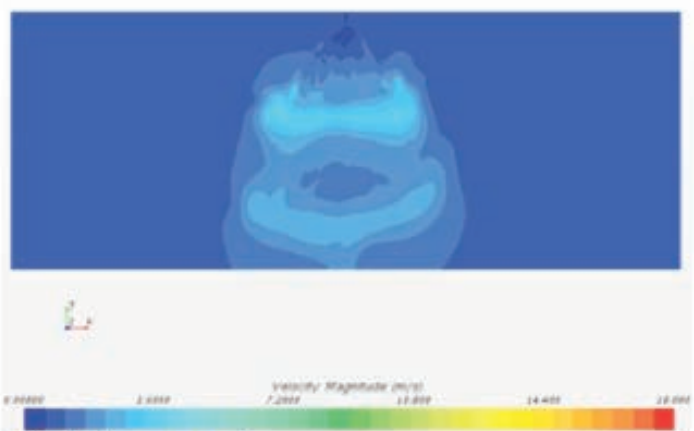

D) 0.2 seconds

Figure 2. A-D) Pulsed simulation velocity magnitude $[\mathrm{m} / \mathrm{s}]$. 


\section{Boundary conditions and meshing}

The geometry was broken into several different regions. The regions can be seen in Figure 1. The boundary conditions corresponding to each region can be seen in Table 1 .

The mesh used for the simulations consisted of approximately 12.5 million cells. A trimmed cell was chosen for the cell type. A mesh study was performed and the trimmed cell method (mostly hexahedral and some tetrahedral) provided better results than the polyhedral or tetrahedral (Chapman, 2020). A volumetric control (variable mesh size) was also used to allow for a finer mesh to be used in the area where the spray plume was expected to flow. Figure $1 \mathrm{~B}$ shows the mesh on a slice through the center of the domain.

\section{Pulsed inlet}

Ideally, pressure boundary conditions would be used for the inlet of the nozzle. However, pressure boundary conditions often lead to less stable simulations. Instead of pressure boundary conditions, velocity boundary conditions were used. To simulate the pulsing of the spray, a user defined function was created for a pulsed velocity inlet. The user defined function used to pulse the velocity is given by Equation 11 .

$$
v(t)=\left\{\begin{array}{c}
v_{\text {in }} \text { when } \sin (6 * f * t) \geq 0 \\
0 \text { when } \sin (6 * f * t)<0
\end{array}\right.
$$

\section{Solver settings}

This problem was simulated as a turbulent and multiphase material problem. The corresponding physics model setup is shown in Table 2.

The Eulerian multiphase model also requires additional models to define the phases and phase interactions. Table 3 shows the selections for the Eulerian phase models and Table 4 shows the selections for the phase interaction models.

\section{Determination of simulation flowrate}

The simulation does not explicitly calculate the volumetric flowrate. To estimate the flow rate, a user defined function was created. The user defined function takes advantage of the uniform mesh used near the center of the geometry to determine the area of the cell normal to the flow. Equation 12 is the equation used to estimate the flowrate.

$$
Q=A_{\text {cell }} V_{\text {mean }}
$$

Because the mesh was not entirely uniform, only the flowrate towards the center of the plume is able to be estimated.

\section{Experimental methods}

A simple cost-effective method was used to measure sprayer pattern. The cups are set up in a 9 by 19 grid where each grid point or mesh point is a cup. One grid point or mesh point is 3 inches $(76.2 \mathrm{~mm})$ by 3 inches $(76.2 \mathrm{~mm})$. The experiment is shown in Appendix Figure 2. The sprayer is activated and sprays for a known amount of time. Each of the cups are then weighed. From the weight of the cup the volumetric flow rate $\left(\mathrm{m}^{3} / \mathrm{s}\right)$ and the spray pattern can be extracted. Due to the current limitations of the testbed, mostly qualitative comparisons, such as spray distribution characteristics, can be made.

\section{Results}

\section{Pulsed nozzle}

As discussed previously, a user-defined function to define the velocity at the inlet of the nozzle was used to pulse the nozzle. The user-defined function would determine whether the nozzle should be spraying based on the time. Results were collected for passive scalar and velocity magnitude. A passive scalar is a dimensionless value that is a less computationally expensive method to visualize the volume fraction. The passive scalar is passive because the addition of the passive scalar does not affect the physical properties of the simulation similar to using a $d y e$. Figure 2 show a series of screenshots of the velocity magnitude from the simulation at a frequency of $10 \mathrm{~Hz}$. The spray distribution from the passive scalar

Table 1. Boundary conditions.

\begin{tabular}{lc} 
Region name & Boundary conditions \\
in1 & Velocity inlet \\
in2 & Velocity inlet \\
\hline front & Symmetry plane \\
back & Symmetry plane \\
\hline left & Symmetry plane \\
right & Symmetry plane \\
\hline out & Outlet \\
nozzle & Wall \\
\hline
\end{tabular}

Table 2. Physics models.

\begin{tabular}{lc} 
Physics model & Selection \\
Space & Three dimensional \\
Time & Unsteady \\
\hline Material & Eulerian multiphase \\
Eulerian multiphase model & Volume of fluid \\
\hline Viscous regime & Turbulent \\
Reynolds-average turbulence & k- $\varepsilon$ turbulence \\
\hline Optional models & Passive scalar \\
& Gravity \\
\hline
\end{tabular}

Table 3. Eulerian phase models.

\begin{tabular}{lcc} 
Phase & Water & Air \\
Material & Liquid & Gas \\
Equation of state & Constant density & Constant density \\
\hline
\end{tabular}

Table 4. Phase interaction models.

\begin{tabular}{ll} 
Model & Selection \\
Phase interaction topology & VOF-VOF phase interaction \\
Optional models & Multiphase interaction \\
& Surface tension force \\
\hline
\end{tabular}

VOF, volume of fluid method. 
can be found in Appendix Figure 3. The series of screenshots start at 0.05 seconds into the spray time. At the start of the simulation, the sprayer is active. At 0.05 seconds, the velocity is turned off and the spray plume is cut off. The spray plume moves down through the domain until fully evacuated. At 0.1 seconds, the spraying process is resumed, and a new spray plume is created. The simulation was ran for 2 seconds simulated time. By time averaging the simulation the spray plume can be visualized. Appendix Figure 4 shows the time averaged spray plume. In reality, the nozzle is set to a pressure of $40 \mathrm{psi}(275.79 \mathrm{kPa})$ at the inlet. As explained earlier, pressure boundary conditions could not be used during the simulation. Instead, velocity boundary conditions were used to provide a more stable simulation. To ensure that the pressure at the inlet of the nozzle stayed at a consistent $40 \mathrm{psi}(275.79 \mathrm{kPa})$ during the simulation, the absolute pressure at the entrance of the nozzle was monitored. Figure 3 shows the pressure at the inlet stays at an approximately constant value of $40 \mathrm{psi}(275.79 \mathrm{kPa})$ during each of the pulses. This supports the use of using the user-defined function to pulse the spray.

\section{Experimental data}

Once the method used to pulse the spray was determined to be working appropriately, the results were compared to experimental

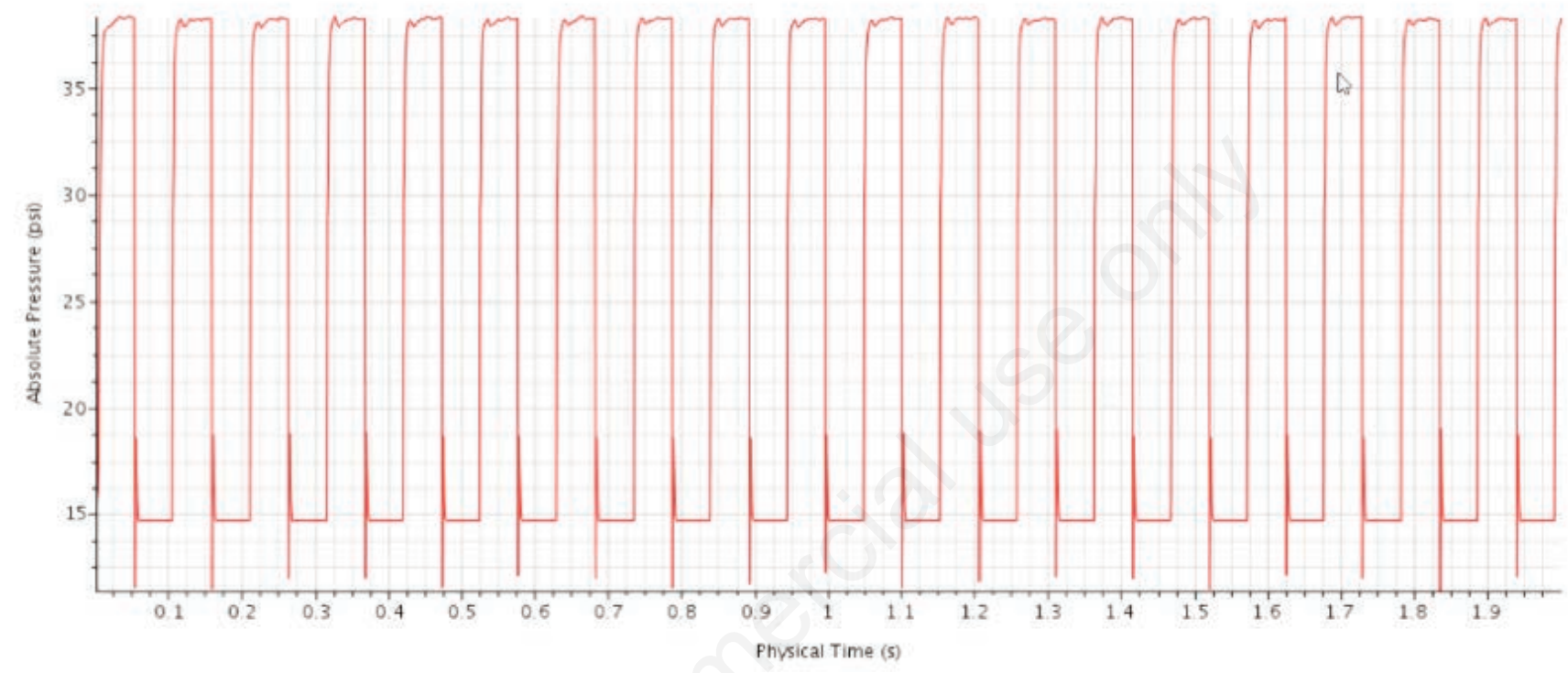

Figure 3. Absolute pressure at entrance of nozzle.

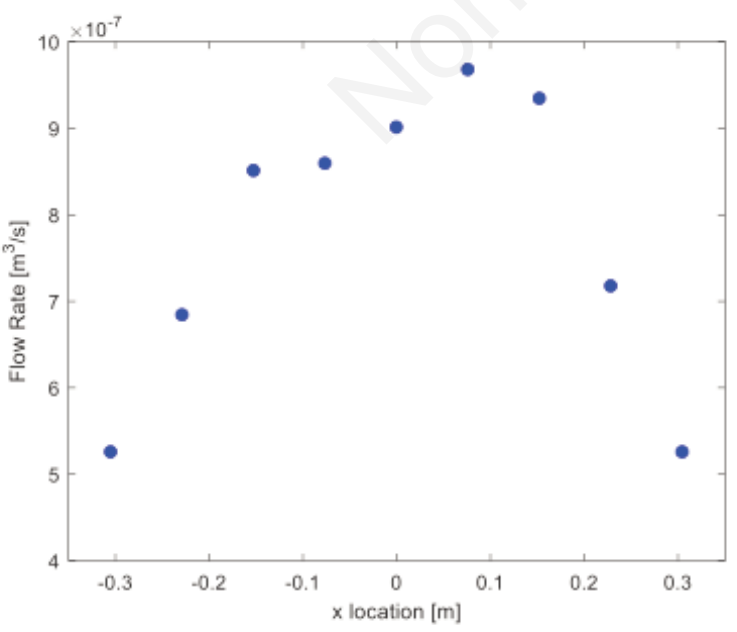

A) Experimental

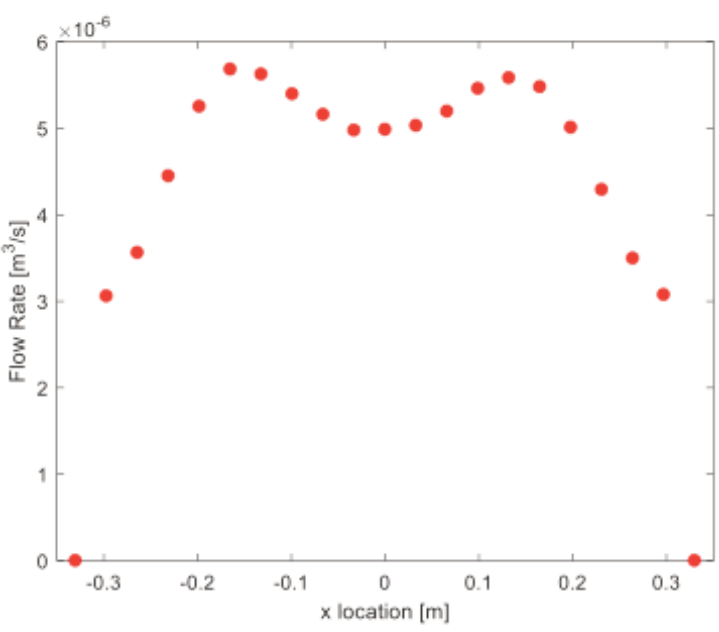

B) Simulation

Figure 4. A-B) Flowrate through center of spray plume $\left[\mathrm{m}^{3} / \mathrm{s}\right]$. 
data collected from a sprayer testbed. The spray distribution on a plane 20 inches $(508 \mathrm{~mm})$ below the tip of the nozzle was compared for both experimental and simulation data. The flow rate through the centerline of the spray plume was extracted for both the simulation and the experimental data. Figure 4 shows a comparison the flow rate at the center of the spray plume in $\mathrm{m}^{3} / \mathrm{s}$. The full flow rate distribution in $\mathrm{m}^{3} / \mathrm{s}$ for the experiment and simulation can be found in Appendix Figure 5.

The simulation flowrate distribution differs from the experimental flowrate. However, similar trends are noticed between the simulated and experimental distributions. The simulation predicts the highest flowrate off the $\mathrm{z}$ axis which is also noticed in the experimental flowrate. The simulation flowrate also becomes lower moving towards the edges of the spray plume which also agrees with the experimental data. When comparing the flowrates at the center of the spray plume, the distributions takes a similar shape. The flowrates are lower in the experimental data. However, this is expected due to the water escaping from the gaps between the cups. The spray angle was also compared to experimental data. The spray angle was determined experimentally using a highspeed camera. A protractor was used to determine the spray angles for both the experiment and the simulation. Figure 5 shows the experimental and simulated spray angle.

The simulated spray angle is around 10 degrees higher than the experimental spray angle. This is most likely due to the mesh used for the simulation. There are several droplets observed in the highspeed camera shot that fall outside of the spray plume used to determine the spray angle. The cell size used for the simulation does not adequately capture the interface between the two phases and is picking up these small amounts of droplets at the edge of the spray plume. These droplets are then distributed throughout the cell resulting in a larger spray angle. This is discussed in (Chapman, 2020).

\section{Frequency effects}

After the spray distribution was verified using experimental data, the effect frequency has on the pulsed spray was investigated.

Frequencies of $10 \mathrm{~Hz}, 20 \mathrm{~Hz}$, and $30 \mathrm{~Hz}$ were investigated. Results for the spray distribution, examined using a time averaged passive scalar, and the time averaged velocity magnitude were collected at a plane 20 inches $(508 \mathrm{~mm})$ below the tip of the nozzle. The time averaged spray plume was also examined.

Figure 6 shows contour plots showing the time averaged spray distribution and time averaged velocity magnitude at a frequency

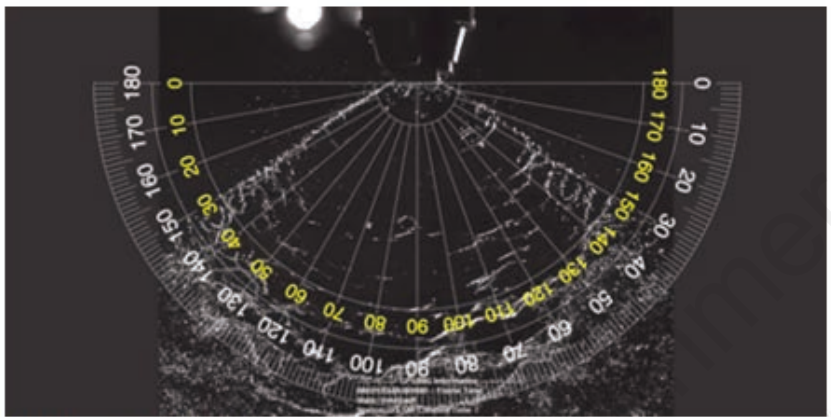

A) Experimental

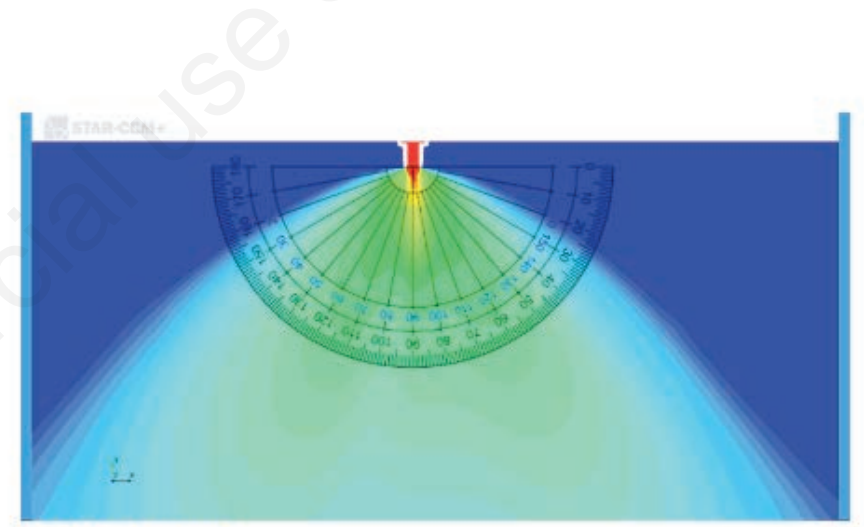

B) Simulated

Figure 5. A-B) Spray angle.

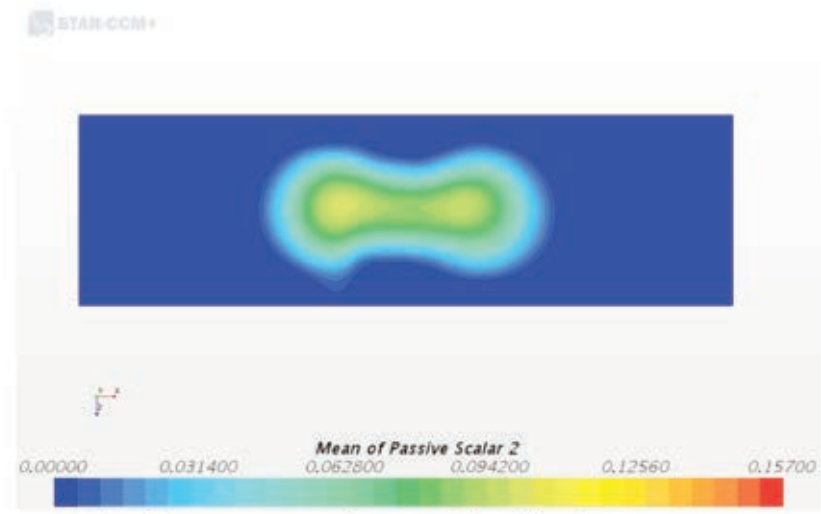

A) Time averaged spray distribution

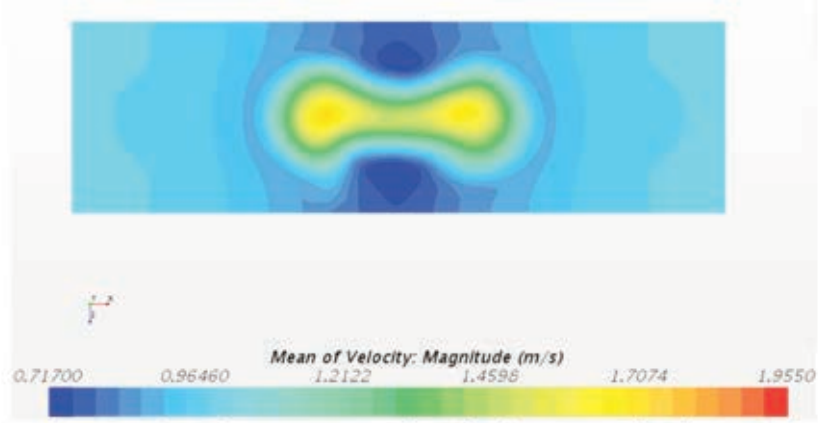

B) Time averaged velocity magnitude

Figure 6. A-B) Results at $10 \mathrm{~Hz}$. 


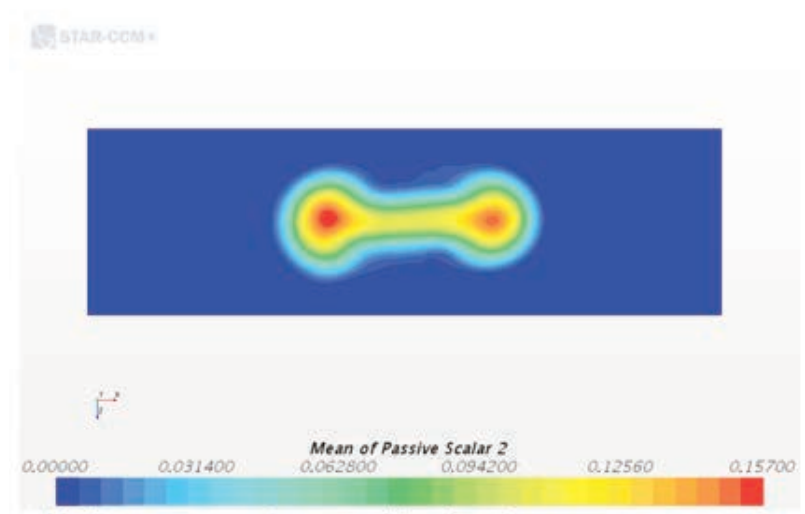

A) Time averaged spray distribution

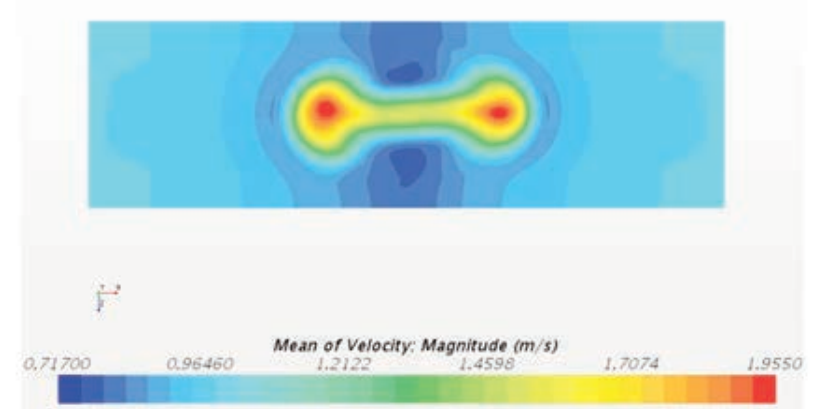

B) Time averaged velocity magnitude

Figure 7. A-B) Results at $30 \mathrm{~Hz}$.

of $10 \mathrm{~Hz}$. The color bars are scaled to allow comparisons to be made to other frequencies. The maximum concentration of the passive scalar at a frequency of $10 \mathrm{~Hz}$ was approximately 0.102 and the maximum velocity magnitude was approximately $1.7 \mathrm{~m} / \mathrm{s}$. The location of the maximum concentration of the passive scalar and the maximum velocity magnitude occurred at the same location. This held true for all frequencies. The time averaged velocity magnitude at the exit of the nozzle was approximately $9 \mathrm{~m} / \mathrm{s}$. The time averaged spray plume can be found in Appendix Figure 6 .

Appendix Figure 7 is a contour plot showing the time averaged spray distribution and time averaged velocity magnitude at a frequency of $20 \mathrm{~Hz}$. The maximum concentration of the passive scalar was approximately .137 and the maximum velocity magnitude was approximately $1.875 \mathrm{~m} / \mathrm{s}$. The location of the maximum values occurs in the same location as the simulation with a frequency of $10 \mathrm{~Hz}$. Again, the time averaged velocity magnitude at the exit of the nozzle was approximately $9 \mathrm{~m} / \mathrm{s}$. However, at distance further from the nozzle, the velocity at the edges of the spray plume remain higher than at $10 \mathrm{~Hz}$. Appendix Figure 8 shows the time averaged spray plume at a frequency of $20 \mathrm{~Hz}$.

Figure 7 shows the time averaged passive scalar and time averaged velocity magnitude at a frequency of $30 \mathrm{~Hz}$. The maximum concentration of the passive scalar was approximately 0.157 and the maximum velocity magnitude was approximately $1.955 \mathrm{~m} / \mathrm{s}$. The velocity near the exit of the nozzle remains the same but again, the velocity at the edges of the spray plume remain higher than at lower frequencies.

As the frequency of the pulses is increased, the spray distribution becomes less uniform. The spray distribution normal to the nozzle becomes higher within the spray plume. At lower frequencies the concentration of the spray is much more spread out. The velocity magnitude also increases downstream of the nozzle. This appears to be caused by the velocity near the edges of the spray plume to remain at higher values as the distance from the nozzle increases. Appendix Figure 9 shows the time averaged spray plume at a frequency of $30 \mathrm{~Hz}$.

\section{Conclusions}

This work looked into the simulation of a pulse-width modulated spray nozzle. First, a method to pulse the spray was determined. The chosen method was to use a user defined function with velocity inlets. This was chosen instead of pressure boundary conditions to allow for a more stable simulation. The absolute pressure was monitored at the entrance of the nozzle. The absolute pressure was at an approximately constant value of 40 psi $(275.79 \mathrm{kPa})$ which verifies that this method can be used. Next, the flowrate at a plane 20 inches $(508 \mathrm{~mm})$ below the tip of the nozzle was examined with both simulation and experimental results. While the results between the experimental data and simulation results do not match up exactly, similar trends of the spray distribution are seen between the experimental and simulation results. Differences between the results could be due to the mesh used for the simulation or the methods to used to capture the experimental data such as water losses through gaps between the cups. Finally, the effects of the frequency of the pulses were examined. Frequencies of 10 $\mathrm{Hz}, 20 \mathrm{~Hz}$, and $30 \mathrm{~Hz}$ were examined. As the frequency is increased, the concentration of the spray plume becomes higher in the center. Increasing the frequency also increases the velocity of the spray. While further investigation is necessary, these results suggest that lower frequencies may provide better results. The lower frequencies provide a more uniform spray distribution which would provide more even coverage during the spraying process. 


\section{Nomenclature}

\begin{tabular}{|c|c|c|c|}
\hline$\rho$ & Density $\left[\mathrm{kg} / \mathrm{m}^{3}\right]$ & $t$ & Time $[\mathrm{s}]$ \\
\hline$v$ & Continuum Velocity [m/s] & $\sigma$ & Stress Tensor $[\mathrm{Pa}]$ \\
\hline$f_{b}$ & Body Forces $\left[\mathrm{N} / \mathrm{m}^{3}\right]$ & E & Total Energy per Unit Mass $[\mathrm{J} / \mathrm{kg}]$ \\
\hline \multirow[t]{2}{*}{$q$} & Heat Flux $\left[\mathrm{W} / \mathrm{m}^{2}\right]$ & $S_{E}$ & Energy Source per Unit Volume \\
\hline & & & {$\left[\mathrm{kg} / \mathrm{m}-\mathrm{s}^{3}\right]$} \\
\hline$\overline{\boldsymbol{v}}$ & Time Averaged Continuum Velocity $[\mathrm{m} / \mathrm{s}]$ & $\bar{p}$ & Time Averaged Pressure $[\mathrm{Pa}]$ \\
\hline $\boldsymbol{I}$ & Identity Tensor & $\overline{\boldsymbol{T}}$ & Mean Viscous Stress Tensor $[\mathrm{Pa}]$ \\
\hline \multirow[t]{2}{*}{$T_{\text {RANS }}$} & Stress Tensor $[\mathrm{Pa}]$ & $\bar{E}$ & Mean Total Energy per Unit Mass \\
\hline & & & {$[\mathrm{J} / \mathrm{kg}]$} \\
\hline$k$ & Turbulent Kinetic Energy [J/kg] & $\mu$ & Dynamic Viscosity [Pa-s] \\
\hline$\mu_{t}$ & Turbulent Viscosity $\left[\mathrm{m}^{2} / \mathrm{s}\right]$ & $\sigma_{k}$ & Model Coefficient $[\mathrm{m} / \mathrm{kg}]$ \\
\hline$P_{k}$ & Production Term $\left[\mathrm{kg} / \mathrm{m}-\mathrm{s}^{3}\right]$ & $\epsilon$ & Turbulent Dissipation Rate $\left[\mathrm{m}^{2} / \mathrm{s}^{3}\right]$ \\
\hline$\epsilon_{0}$ & Ambient Turbulence Level $\left[\mathrm{m}^{2} / \mathrm{s}^{3}\right]$ & $S_{k}$ & Source Term $\left[\mathrm{kg} / \mathrm{m}-\mathrm{s}^{3}\right]$ \\
\hline$\sigma_{\epsilon}$ & Model Coefficient [m/kg] & $T_{e}$ & Large-Eddy Time Scale [s] \\
\hline$C_{\epsilon 1}$ & Model Coefficient & $P_{\epsilon}$ & Production Term $\left[\mathrm{m}^{2} / \mathrm{s}^{3}\right]$ \\
\hline$C_{\epsilon 2}$ & Model Coefficient & $f_{2}$ & Damping Function \\
\hline$T_{0}$ & Time Scale [s] & $S_{\epsilon}$ & Source Term $\left[\mathrm{m}^{2} / \mathrm{s}^{3}\right]$ \\
\hline$\alpha_{i}$ & Phase Volume Fraction & $V_{i}$ & Volume of Phase $i\left[\mathrm{~m}^{3}\right]$ \\
\hline$V$ & Volume of Cell $\left[\mathrm{m}^{3}\right]$ & $f$ & Frequency $[\mathrm{Hz}]$ \\
\hline$v_{\text {in }}$ & Inlet Velocity [m/s] & $A_{\text {cell }}$ & Area of the cell $\left[\mathrm{m}^{2}\right]$ \\
\hline$V_{\text {mear }}$ & Mean Velocity of the cell & & \\
\hline
\end{tabular}

\section{References}

Bade K., Kalata W., Schick R. 2010. Experimental and computational study of a spray at multiple injection angles. ILASS Americas, $22^{\text {nd }}$ Annual Conference on Liquid Atomization and Spray Systems, Cincinnati, OH, USA.
Siemens, 2020. Available from: https:/www.plm.automation. siemens.com/global/en/products/simcenter/STAR-CCM.html, Accessed: 01 January, 2020.

Chapman Z. 2020. Using computational fluid dynamics to accurately model agricultural spray nozzles. Degree Diss. South Dakota State University.

Dekeyser D., Duga A.T., Verboven P., Endalew A.M. 2013. Assessment of orchard sprayers using laboratory experiments and computational fluid dynamics modelling. Biosyst. Engine. 157:169-214.

Endalew A.M., Debaer C., Rutten N., Vercammen J., Delele M.A., Ramon H., Nicolai B., Verboven P. 2020. A new integrated cfd modelling approach towards air-assisted spraying part ii: Validation for different sprayers types. Comput. Electron. Agricult. 137:147-71.

Ferziger J., Peric M. 2002. Computation methods for fluid dynamics. $3^{\text {rd }}$ ed. Springer International Publishing, New York, NY, USA.

Moukalled F., Mangani L., Darwish M. 2016. The finite volume method in computational fluid dynamics. Springer International Publishing, New York, NY, USA.

Sidamed M., Taher M., Brown R. 2005. A virtual nozzle for simulation of spray generation and droplet transport. Biosyst. Engine. 295:307-92.

TeeJet Technologies. 2013. A user's guide to spray nozzles. Available: http://www.teejet.com/

TeeJet Technologies. 2020. A user's guide to spray nozzles. Available: http://www.teejet.com/

Tryggvason G., Scardovelli R., Zaleski S., 2011. Direct numerical simulations of gas-liquid multiphase flows. Cambridge University Press, Cambridge, UK.

United States Environmental Protection Agency. 2019. Introduction to pesticide drift. Available from: http://www.epa.gov/reducing-pesticide-drift/introduction-pesticide-drift\#effects 